\title{
Avaliação como estratégia de desenvolvimento da cultura da participação: uma experiência no ensino fundamental
}

\author{
Raquel Ruppenthal \\ Cadidja Coutinho
}

Mara Regina Bonini Marzari

\section{Resumo}

A organização do ensino em sala de aula envolve diversas atividades, como o planejamento, implementação e a avaliação, que além de verificar a aprendizagem, deveria propiciar autonomia para a autogestão da formação por parte dos alunos. Assim, o objetivo desse trabalho é relatar a utilização de estratégias de avaliação diversas. Trata-se de um trabalho qualitativo, de caráter exploratório, realizado com cinco turmas de ensino fundamental. Para a coleta de dados utilizou-se observação e depoimentos dos alunos. As estratégias utilizadas foram a autoavaliação ao final de cada aula (Estratégia 1); atividades de produção textual utilizando linguagens diversas (Estratégia 2); e ao final do estudo da unidade realizou-se rodas de conversa, nos quais se avaliava os aspectos metodológicos positivos e negativos, bem como os conhecimentos construídos (Estratégia 3). Observou-se que a condução de diálogos para proporcionar aos alunos a consciência do aprendizado e/ou dificuldades foi importante para modificar atitudes em aula. Avaliar o aprendizado por meio de produções e não apenas com provas tradicionais, se mostrou viável para a maioria dos estudantes, apesar de alguns alunos afirmarem preferir provas. A estratégia 3 foi a mais interessante do ponto de vista do exercício de participação. Essa abertura para os alunos analisar e avaliar os diferentes momentos das sequências didáticas permitiu que os mesmos se envolvessem mais nas aulas posteriores. Ao mesmo tempo, essas estratégias possibilitam desenvolver a cultura da participação, habilidade de extrema valia no exercício da cidadania e democracia.

Palavras-chave: Avaliação; cultura da participação; instrumentos de avaliação. 


\section{Evaluation as a strategy for development of culture of participation: an experience in elementary school}

The organization of teaching in the classroom involves several activities, such as planning, implementation and, evaluation, which in addition to verifying learning, should provide autonomy for the self-management of training by students. Thus, the objective of this work is to report the use of different evaluation strategies. This is a qualitative, exploratory study carried out with 5 classes of elementary school. For data collection, students' observations and testimonies were used. The strategies used were self-assessment at the end of each class (Strategy 1); production activities using different languages (Strategy 2); and at the end of the study of the unit there were moments of conversation, in which positive and negative methodological aspects were evaluated, as well as the constructed knowledge (Strategy 3). It was observed that conducting dialogues to provide students with an awareness of learning and/or difficulties was important in modifying attitudes in class. Evaluating learning through productions and not just with traditional tests have proved feasible for most students, although some students claim to prefer proofs. Strategy 3 was the most interesting from the point of view of the participation exercise. This openness for students to analyze and evaluate the different moments of the didactic sequences allowed them to become more involved in later classes. At the same time, these strategies make it possible to develop the culture of participation, an ability of extreme value in the exercise of citizenship and democracy.

Keywords: Evaluation; culture of participation; evaluation tools. 


\section{Introdução}

A avaliação é uma prática constante do processo educacional em qualquer nível de ensino. Apesar da sua presença permanente nos espaços educativos, muitas vezes ela é realizada de forma automática, sem a devida reflexão acerca da sua função ou ocorre com base nos antigos modelos educativos cuja ênfase está na memorização. Porém a avaliação poderia ser uma possibilidade para desenvolver a autonomia e a cultura de participação, tão importante numa sociedade que se postula democrática.

O processo avaliativo, em geral, representa um "problema", tanto para o professor quanto para o aluno (GATTI, 2003; GATTI, 2008; SAUL, 2008). Para o professor, o desafio está em organizar e sistematizar a avaliação de forma que consiga atender a demanda em todas as turmas. Para o aluno, o problema muitas vezes está na preparação para a avaliação e no controle emocional durante a avaliação e a ideia de que a avaliação tem como função apenas dar uma nota. No entanto, a avaliação deveria ser um momento importante para o professor e o aluno, planejado para uma função além da classificação. O professor ao explicitar as estratégias de avaliação pode verificar se o objetivo da atividade foi alcançado; o aluno, ao realizar a avaliação, deveria ter condições de acompanhar o seu progresso ou dificuldades.

Assim, o presente trabalho aborda a questão da avaliação, no contexto de sala de aula, numa perspectiva de emancipação visando a autonomia, desenvolvimento e participação. Para tanto, inicialmente busca-se na literatura embasamento relativo a compreensões acerca da avaliação e seus objetivos para a seguir descrever a avaliação numa perspectiva de emancipação do estudante. Na sequência, indica o embasamento metodológico de coleta e análise de dados, seguida do relato e discussão dos resultados, para apresentar as considerações acerca da experiência.

\section{Breve revisão sobre a avaliação}

A avaliação é integrante do processo de ensino-aprendizagem, e como tal, vem sendo objeto de pesquisa. A avaliação "é uma reflexão sobre o nível de qualidade do trabalho escolar tanto do professor como do aluno" (LIBÂNEO, 2013, p. 216). Para Luckesi (2011) pelo planejamento decidimos o que construir e a avaliação nos oferece subsídios para verificar como estamos em relação a esta decisão. A partir da avaliação é possível ao docente a tomada de decisão em relação ao que deve ser feito. Ou seja, a avaliação está diretamente ligada ao processo de ensino-aprendizagem e como tal, deve ser uma atividade planejada conscientemente para que possa buscar informações para orientar o planejamento das etapas posteriores.

Percebe-se com esta descrição que a avaliação precisa de um caráter que vá além de meramente reconhecer a aprendizagem ocorrida. Além disso, a avaliação precisa reconhecer 
aquilo que representa dificuldade de modo que a organização da prática pedagógica possa intervir para facilitar a compreensão e construção de conhecimentos. A realização de provas ou testes com o único objetivo de verificar o que foi aprendido torna a avaliação um processo automático, sem qualquer reflexão acerca do significado de avaliar.

As considerações de Luckesi (2011) caminham na mesma direção, ao indicar que a avaliação deve apontar a qualidade da aprendizagem do educando, visando trazer à tona aspectos essenciais e que possibilitem ao educador, decidir os rumos de sua prática pedagógica. Se o objetivo final dos processos educativos é formar para a cidadania, participação e preparação para o mercado de trabalho (LDB, 1996), parece óbvio que utilizar a avaliação apenas com o objetivo de atribuir uma nota não é compatível com o desenvolvimento individual e coletivo. Nesse ínterim, a avaliação deveria ser tratada como um processo coletivo, no qual aluno e professor reorganizam suas ações na sala de aula a partir do diagnóstico.

Conforme Poltroniere; Calderón (2012), há uma tradição acerca das pesquisas sobre a avaliação na educação básica no país, que culmina com uma variedade de periódicos cujo escopo de publicação é relativo a avaliação. Acrescentam ainda, que o estudo sobre a temática avaliação não deve ser realizada sem considerar as concepções político-filosóficas sobre a função e objetivo da avaliação na educação. Da mesma forma Meneghel; Kreish (2009) descrevem e destacam que por trás da avaliação existem concepções que interferem no planejamento do processo avaliativo desenvolvido nas salas de aula e nas demais atividades escolares.

De acordo com Libâneo (2013) é possível atribuir no mínimo três funções para a avaliação: pedagógico-didática, de diagnóstico e de controle. Essas funções não ocorrem de forma isolada, uma vez que cada uma delas tem uma finalidade e que fazem sentido de forma conjunta. A função pedagógico-didática refere-se a comprovar se os objetivos de aprendizagem foram ou não alcançados. Poderia dizer-se que essa é uma visão ampla de como processo pedagógico se encaminha, sem detalhar aspectos relativos aos saberes.

Diferente da função anterior, a avaliação com função de diagnóstico busca identificar progressos e dificuldades a fim de que o planejamento possa ser adaptado, ou seja, aprofunda a compreensão acerca do aprendizado, descrevendo aspectos que são dificuldades ou fragilidades no processo de elaboração do conhecimento. A avaliação com função diagnóstica é valiosa para o planejamento da prática pedagógica. Por fim, a função de controle da avaliação remete aos meios e frequência das certificações e qualificação dos resultados. Nessa perspectiva, a avaliação tem como fim o registro da trajetória formativa do aluno e é utilizada para a formulação de pareceres, conceitos ou notas que constituem os boletins e históricos escolares (LIBÂNEO, 2013)

É importante ressaltar que estas três funções não são excludentes entre si, mas que ISSN 2526-2882 
são complementares no processo avaliativo. Apesar da avaliação compreender funções distintas, que devem ocorrer de modo equilibrado, há situações ou mesmo sistemas de ensino que dão ênfase a função didático-pedagógica ou de controle, em detrimento da função diagnóstica.

Nesse sentido, conforme a função predominante da avaliação, é possível organizar as práticas avaliativas em torno de três grandes perspectivas: classificatória, diagnóstica e emancipatória (MENEGHEL; KREISH, 2009; SAUL, 2008). Cabe dizer que cada uma dessas concepções está alinhada a teorias de currículo e teorias de educação específicas, que não serão abordadas nesse texto. Convém uma descrição dessas concepções no que concerne o entendimento sobre avaliação e a relação existente entre avaliação e construção de conhecimento.

Sob a perspectiva de avaliação classificatória, o objetivo final do instrumento avaliativo utilizado é "medir" a retenção dos conteúdos pelo aluno. Com base na quantidade de informação memorizada, é possível atribuir uma nota ou classificar o aluno de acordo com uma escala (bom, regular, insuficiente) (MENEGHEL; KREISH, 2009). Normalmente, nessa concepção avaliativa, a avaliação ocorre ao final de uma unidade de estudo ou ao final do trimestre, e não há espaço para a reflexão acerca do que significam a nota ou conceito atribuídos. É uma perspectiva que ainda é muito visível em toda comunidade escolar pois está relacionada a retenção ou progressão do aluno. Denota a preocupação de seguir o curso escolar, e não com a aprendizagem.

A concepção diagnóstica da avaliação é compreendida como um meio de identificar as fraquezas e potencialidades dos estudantes a fim de nortear o planejamento (MENEGHEL; KREISH, 2009). A partir desse diagnóstico é possível propor a reflexão acerca do saber, levando a corresponsabilidade no processo de ensino-aprendizagem. $\mathrm{O}$ aluno pode ter um papel bem ativo o que contribui para o desenvolvimento de uma cultura da participação. Conforme Luckesi (2011), a avaliação diagnóstica deve ter o caráter de um instrumento auxiliar da aprendizagem e não um de um instrumento de aprovação ou reprovação. Deve estar preocupada com o crescimento do aluno. Isso demonstra que o foco da avaliação diagnóstica está no desenvolvimento cognitivo.

Na avaliação com concepção emancipatória, tem-se como princípio que os alunos sejam capazes de orientar-se por si mesmos e ao analisar as próprias dificuldades, agir para superá-las (MENEGHEL; KREISH, 2009). Nesse sentido, a avaliação é uma ferramenta que estimula o aluno a desenvolver a autonomia e a consciência de como ele constrói o conhecimento. $\mathrm{O}$ aluno é o verdadeiro protagonista no processo avaliativo pois através da consciência dos limites e das necessidades, aliam-se metas de superação que podem contribuir para a qualidade da aprendizagem do aluno e não apenas a sua classificação (LUCKESI, 2011). 
Como o objetivo principal do trabalho é demonstrar que a avaliação pode contribuir para a cultura da participação e autonomia, a próxima seção visa aprofundar aspectos teóricos relativas a avaliação emancipatória.

\section{A avaliação como promotora de emancipação}

Para que se compreenda a importância de prática avaliativas emancipatórias, cabem outras considerações acerca da avaliação. Quando se fala em avaliação na sala de aula, a reação típica ainda é o medo. No prefácio da obra de Demo, Gadotti afirma que "avaliar pode constituir um exercício autoritário do poder de julgar ou, ao contrário, pode constituir um processo e um projeto em que o avaliador e o avaliado buscam e sofrem mudanças" (DEMO, 2005, p. x). Assim, o processo avaliativo pode ser utilizado apenas para classificar o estudante como apto ou não apto; mas também pode ser utilizada como instrumento de intervenção para auxiliar o estudante na superação da dificuldade verificada.

A avaliação tem como objetivo acompanhar o processo de aprendizagem, além de compreender como o processo de aprendizagem está ocorrendo (GATTI, 2003). Dessa forma, a avaliação permite obter informações importantes para o planejamento e replanejamento das atividades pedagógicas. Assim, ao planejar a aula e as atividades para a sala de aula o professor já deve ter claro quais estratégias avaliativas serão utilizadas a fim de que obtenha esse diagnóstico do processo de aprendizagem. Ou seja, as concepções do docente acerca de educação, sociedade e objetivos da escola interferem nas estratégias de avaliação utilizadas.

Por outro lado, o formato e o objetivo da avaliação acompanham as concepções de educação que embasam a prática do professor. Ou seja, a avaliação está fundamentada numa filosofia de ensino. Se o objetivo da escola é entendido apenas como transmissão de conhecimento, em geral a avaliação acaba "medindo" apenas a capacidade do aluno em reter/decorar informações (MENEGHEL, KREISH, 2009).

Ao considerar que vivemos um momento em informações (verdadeiras e falsas) estão disponíveis a um clique, parece que a capacidade para a qual precisamos mobilizar os indivíduos é a habilidade de avaliar a veracidade e confiabilidade das mesmas. Nesse sentido, importa preparar o aluno para que ele seja crítico, autônomo e independente nesse processo. Esse fato leva a refletir sobre a avaliação que apenas mede a memorização de conteúdos. Apesar disso, as provas ainda são vistas como um instrumento que "mede" a aprendizagem e são praticamente o único tipo de instrumento utilizado para realizar a avaliação nas escolas. $\mathrm{E}$ a partir dessas, o aluno recebe uma nota, que em geral é visto como a finalidade da avaliação (GATTI, 2003).

É importante salientar que reconhecemos o valor e a importância da prova. Porém, há aspectos que precisam ser considerados para que a prova realmente seja efetiva para o 
desenvolvimento e aprendizagem dos alunos. Concordamos com Gatti (2003) que afirma que a prova precisa ser elaborada de forma a acionar a utilização dos conhecimentos construídos, acessando os diferentes estilos de aprendizagem e a variedade de linguagens. Nesse sentido, podemos perceber que há diversas formas de organizar uma avaliação. Se ela apenas solicita ao aluno a devolução de informações, a avaliação apenas reproduz a concepção classificatória. Quando uma prova é organizada com o objetivo de mobilizar informações, habilidades para solucionar problemas ou assumir posicionamento frente a um tema, tem-se uma avaliação que valoriza a capacidade crítica, a autonomia e a emancipação do indivíduo.

Pelo exposto na primeira parte desta seção, percebe-se que a avaliação não pode ter um caráter finalista, no entanto deve ser compreendida como um meio para o autodesenvolvimento do aluno e também do professor. Assim, pode-se dizer que a avaliação deveria se preocupar com a autonomia do aluno em relação ao processo de aprendizagem. A autonomia tem relação com o indivíduo assumir seu papel no processo, de forma consciente e reflexiva. Essas percepções sobre a avaliação e autonomia do indivíduo são coerentes com as concepções de educação crítico-libertadora (FREIRE, 1996), que escape a educação transmissiva e/ou bancária. Nesse sentido, Saul (2008) propõe a avaliação emancipatória.

As referências teórico-metodológicas da avaliação emancipatória são a avaliação democrática, a crítica institucional, a criação coletiva e a pesquisa participante constituindo uma matriz de ação que visa a análise e crítica da realidade, objetivando a transformação (SAUL, 2008). Democrática, pois visa a participação de todos; crítica, no sentido de a escola perceber-se como um ser pensante e não reprodutor dos ideais do poder dominante; criação coletiva, para que todos se engajem na solução de problemas ou tomada de decisões; e enfim, pesquisa participante, pois não há ensino-aprendizagem fora da pesquisa (FREIRE, 1996; SAUL, 2008). Na perspectiva da avaliação emancipatória, o professor continua com uma função importante, mas o estudante também é um sujeito ativo no processo.

Na perspectiva emancipatória, o processo de ensino-aprendizagem passa a ser a fonte de dados/informações para que professor e aluno reconheçam as lacunas e potencialidades. Após a obtenção dessas considerações, é importante que se estabeleça um processo de reconstrução e aprimoramento dos saberes. Dessa forma, devem utilizar-se continuamente uma variedade de instrumentos (SAUL, 2008; LUCKESI, 2011; LIBÂNEO, 2013). E essa variedade de instrumentos deve estar colocada à disposição e serviço do aluno, para que ele tenha consciência sobre onde está, e a partir disso, propor onde quer chegar. Por isso, Saul (2008) indica que a avaliação emancipatória está voltada para o futuro, porém com bases no presente.

A legislação educacional propõe que uma das finalidades da educação é promover o desenvolvimento e a cidadania para a participação democrática na sociedade. Assim, é possível 
estabelecer um paralelo entre os processos avaliativos e a formação. Luckesi (2011) afirma que a sociedade democrática tem como base as relações de reciprocidade e para tal, inúmeras competências são necessárias, entre elas a capacidade de posicionar-se, propor soluções, bem como respeitar ideias antagônicas. Por isso, a avaliação não pode estar voltada apenas para a nota, mas precisa ser compreendida como uma ação consciente do processo como um todo, pois a “avaliação é um constante olhar crítico sobre o que está se fazendo" (LUCKESI, 2011, p. 135).

Assim, Saul (2008) salienta que a avaliação emancipatória é marcada pela função diagnóstica; favorece o autoconhecimento contribuindo para que o aluno se torne sujeito do seu processo de aprendizagem. Além disso, tem compromisso com a educação democrática, com a inclusão e com a própria relação pedagógica. Por priorizar aspectos qualitativos, ajuda o educando a aprender e o professor a planejar e replanejar sua ação.

Apesar dos discursos educacionais relativos ao ideal emancipatório da avaliação, a herança cultural da avaliação classificatória permanece nas escolas (MENEGHEL; KREISH, 2009). Porém, é necessário superar essa concepção. E uma das formas para alcançar uma avaliação que sirva ao estudante e a escola passa pela implementação de estratégias variadas de avaliação, em diferentes momentos, e principalmente, que o sujeito avaliado assuma papel ativo durante a avaliação. Assim, o presente trabalho descreve os resultados da utilização de três estratégias, cujo objetivo é fomentar a cultura da participação do estudante no processo avaliativo.

\section{Metodologia}

O presente trabalho pode ser enquadrado como uma pesquisa qualititativa (FLICK, 2013) uma vez que a busca, coleta e análise de dados e é vinculada a interpretação e descrição do fenômeno em estudo. Quanto aos objetivos, trata-se de pesquisa exploratória e descritiva (ANDRADE, 2009; GIL, 2008), pois visa o aprofundamento da temática a partir da utilização de diferentes formas e estratégias de avaliação que poderiam interferir na dinâmica de colaboração e participação na sala de aula.

Quanto aos métodos, pode ser classificada como uma pesquisa-ação que

é um tipo de pesquisa social com base empírica que é concebida e realizada em estreita associação com uma ação ou com a resolução de um problema coletivo e no qual os pesquisadores e os participantes representativos da situação ou do problema estão envolvidos de modo cooperativo ou participativo (THIOLLENT, 2008, p. 16).

A pesquisa ocorreu em uma escola pública, no interior do estado do RS. O público participante foram cinco turmas dos anos finais do ensino fundamental e a professora de 
ciências. A professora atuou como professora-pesquisadora. As aulas de ciências foram ministradas normalmente, conforme o planejamento da professora, em geral organizadas conforme os três momentos pedagógicos (DELIZOICOV, ANGOTTI, PERNAMBUCO, 2011). A ação decorrente da pesquisa foi a inserção de três estratégias avaliativas com foco na participação, em diferentes momentos do planejamento didático.

A Estratégia 1 reunia técnicas para autovaliação, realizadas ao final de cada aula. A autoavaliação pode ser compreendida como uma forma de autoregulação de seus próprios processos de pensamento e aprendizagem (PERRENOUD, 1999). Assim, ao final de cada aula, destinava-se um momento para retomar as ideias principais da aula e para cada um dos tópicos, os alunos deveriam analisar o seu nível de compreensão da aula de acordo com níveis pré-estabelecidos a fim de elaborarem uma avaliação de si mesmos em relação a aula.

A Estratégia 2 consistiu em substituir a avaliação formal no estilo de teste ou prova por atividades de produção textual. Essas atividades pressupõem a utilização de conceitos e criatividade para elaborar um produto. Exemplificam-se como tarefas desse tipo a produção de histórias em quadrinhos, poesias, paródias, vídeos, cartazes entre outros. Em geral, as produções também eram utilizadas em pequenas exposições no espaço escolar ou para leitura entre os pares.

A Estratégia 3 pode ser denominada como roda de conversa ou conselho de sala. Durante estas, avaliou-se aspectos relativos à aprendizagem, bem como aspectos positivos e negativos em relação à condução das aulas. Era um momento semelhante a um Conselho de Classe, porém acontecendo numa escala menor, realizados no final das unidades de estudo.

Para a construção desse trabalho, os dados foram coletados por meio de observação participante realizadas pela professora-pesquisadora, registrados na forma de diário. Também registraram-se falas e considerações dos alunos durante a efetuação das estratégias. Por fim, também foram consideradas as produções dos alunos. Com os dados das cinco turmas e o diário foi possível estabelecer parâmetros e considerações sobre a relação entre avaliação diferenciada e o desenvolvimento da cultura da participação, relatados na próxima seção.

\section{Resultados e discussão}

Participaram 45 alunos do $6^{\circ}$ ano, 51 alunos do $7^{\circ}$ ano e 24 estudantes do $8^{\circ}$ ano, com idades entre 10 e 16 anos. A execução da pesquisa se deu ao longo de 2017 e 2018, numa escola pública estadual. Inicialmente, os resultados serão apresentados de forma independente para cada estratégia utilizada a fim de que explorar e discutir os achados com maior detalhamento. Ao final desta seção, apresentam-se as considerações sobre os efeitos das estratégias 1, 2 e 3 no quesito participação. 


\section{Estratégia 1- Aprendendo a autoavaliar}

Em relação a Estratégia 1, relativa a autoavaliação é importante destacar que no começo dessa prática, houve uma certa relutância em participar, principalmente entre os alunos do $6^{\circ}$ ano. Noutras turmas, nem todos os estudantes se engajaram. Isso pode ser explicado pelo fato de que as práticas de autoavaliação ainda são relativamente escassas no Ensino Fundamental (LUCKESI, 2011). Dessa forma, foi necessário que a docente-pesquisador apresentasse estratégias diversas, a fim de estimular a autoavaliação. Dentre essas técnicas, citam-se a utilização de emojis, imagens e palavras que pudessem representar pelo menos três níveis para a autoavaliação.

Superada essa resistência inicial, aos poucos os alunos foram se habituando a realizar a autoavaliação ao final da aula. No entanto, não podemos afirmar que a totalidade dos alunos aderiu a essa prática. Foi possível observar que uma boa parcela dos alunos a perceber que a autoavaliação auxiliava na percepção precoce das dificuldades. Essa constatação permitiu planejar ações preventivas, que iam desde o estudar com um colega até questionar o professor nas aulas seguintes.

De forma geral, é possível dizer que após a aceitação da autoavaliação enquanto atividade final da aula, houve uma modificação na postura de muitos alunos em sala de aula. A fala que melhor exemplifica essa percepção foi feita por um grupo de alunas do $8^{\circ}$ ano, ao afirmar que a autoavaliação auxilia para "tomar consciência do que a gente aprendeu bem ou nem tão bem ainda”. Depreende-se com esse dizer os primeiros passos em direção a emancipação, ou seja, a capacidade de perceber por si mesmos o que está compreendido daquilo que ainda precisa atenção. Saul (2008) indica que favorecer o autoconhecimento do processo de aprendizado e avaliação pelo aluno contribui para emancipação do indivíduo. Nesse sentido, parece que vale a pena insistir na tarefa de autoavaliação.

\section{Estratégia 2 - Atividades de produção}

Quando o professor aplica provas tradicionais, situações como o nervosismo e o branco na hora da prova são comuns. Outra desvantagem da prova, é que o aluno pode simplesmente decorar a informação, o que não caracteriza a aprendizagem. Além disso, nas provas há uma facilidade para a utilização de meios ilícitos na obtenção de resultados (cola). Nesse sentido, a Estratégia 2 que se utilizou de elaboração de materiais relativos ao conteúdo em estudo se mostrou interessante.

O primeiro aspecto que vale destacar é a importância de considerar a criatividade mobilizada para elaborar as produções. Conforme Oliveira e Alencar (2012), a escola em si deveria proporcionar mais oportunidades para os alunos utilizar o processo criativo nas atividades escolares. Os mesmos autores apontam que um ambiente que estimula o 
pensamento criativo possibilita motivação para uma aprendizagem mais significativa. Nesse sentido, ao afastar o processo avaliativo de provas e aproximar de um contexto no qual a criatividade deveria ser empregada, foi possível observar maior envolvimento por parte da maioria dos estudantes, bem como possibilitar uma avaliação mais realista da aprendizagem dos alunos.

Além disso, avaliar num contexto de produção criativa, permite ao professor perceber se houve apropriação conceitual de fato, ou se o aluno apenas decorou. Nos momentos dedicados a segunda estratégia de avaliação, forneciam-se opções de formatos a ser produzidos, de forma a atender aos diferentes estilos de expressão dos alunos. Assim, normalmente dava-se como opções a produção de histórias em quadrinhos ou produção de poesia ou paródias musicais. Em outros momentos, a escolha se dava em torno da produção de um jogo de tabuleiro, jogo de equipe ou brincadeira, de acordo com o conteúdo em questão. Em qualquer dos formatos, aspectos conceituais normalmente ficavam bem explícitos.

Um aspecto elencado pelo professora no diário de campo é a dificuldade inicial apresentada para efetuar a correção de tais trabalhos. Importante ressaltar que a correção desses trabalhos requer uma sistemática diferente. Se na correção de provas e testes utilizamse chaves de correção, para corrigir uma história em quadrinhos, é necessário que o professor elabore um roteiro com os itens a serem observados na avaliação. Por vezes, esses itens poderão apresentar diferentes níveis de apropriação de conceitos por parte do aluno. A fim de que a correção não seja subjetiva ao ponto de produzir embaraços, o professor precisa ter esse roteiro de correção explicitado claramente.

Porém, é importante salientar que nem todos os alunos aprovaram esta forma de avaliação. Houve aqueles alunos que afirmaram que "preferiam que a avaliação do conteúdo fosse prova". Talvez seja um reflexo do estilo de avaliação da educação tradicional que está enraizada nesses alunos, mas não podemos desconsiderar o fato de os alunos perdem o interesse em atividades que utilizam a criação artística. No entanto, se considerarmos que para resolver problemas ou desafios que se colocam no dia a dia, muitas vezes não basta recorrer ao uso de informações prontas. Em geral, é necessário que se utilize as informações de uma forma diferente ou inovadora, o que envolve um processo criativo e de iniciativa, o que justifica a utilização de estratégia 2.

\section{Estratégia 3 - Conselhos de sala de aula}

No decorrer do ano letivo muitas vezes ocorrem problemas entre turmas e professor, em geral decorrentes da falta de uma comunicação eficaz entre as partes. Citam-se como consequências da falta de comunicação o desinteresse em aula, a falta de atenção nas explicações fornecidas, que por sua vez leva a dificuldade na aprendizagem. Muitas vezes, não 
há abertura para o diálogo, o que dificulta ainda mais a relação professor-aluno. Uma tentativa no sentido de minimizar esse problema foi instaurar a Estratégia 3, equiparável a um conselho de classe, porém apenas para a participação do professor e da turma.

A professora-pesquisadora observou que assuntos que poderiam ser resolvidos entre a turma e o professor acabavam sendo levados ao Conselho de Classe da escola, expostos para sujeitos que não tinham o poder de modificar ou resolver o problema. Outras vezes, a forma como a queixa era colocada no conselho gerava um desgaste emocional que além de improdutivo gerava mal-estar. Assim, numa tentativa de minimizar intervenções nãoconstrutivas no conselho de classe da escola, a professora-pesquisadora planejou praticar uma dinâmica de avaliação das sequências didáticas aplicadas.

A estratégia utilizada foram rodas de conversa para analisar as sequências didáticas finalizadas. Nesse momento, o grupo retomava os principais pontos da sequência de atividades realizadas de forma sucinta e anotava-se no quadro. Na sequência, cada uma das atividades era analisada quanto a aspectos positivos e negativos da aplicação. Ao mesmo tempo, estimulava-se a reflexão acerca da postura individual e se estas, facilitaram ou não a aprendizagem. Além disso, era um momento para indicar estratégias que utilizadas pelo professor foram importantes para a construção da aprendizagem pelos alunos, auxiliando na ação-reflexão por parte do professor-pesquisador.

Porém, inicialmente houve uma certa relutância em falar abertamente durante o processo. Foi necessário convencer os alunos de que ninguém seria prejudicado ou beneficiado por participar. Isso pode estar relacionado com o fato de que poucas vezes os alunos realmente são convidados a participar ou mesmo não tem suas falas ouvidas. No entanto, como toda proposição que foge as práticas habituais, esse estranhamento inicial era esperado. Com o passar do tempo, os alunos passaram a aceitar a proposta de rodas de conversa, participaram menos timidamente e acabaram percebendo que era um momento onde o diálogo era utilizado para resolver problemas e/ou conflitos.

\section{O que se observou com a proposta de avaliação}

Ao considerar que o pressuposto de gestão nas escolas é a gestão democrática, parece ser importante que se promovam práticas que fomentem uma cultura de participação, visando preparar os indivíduos para a participação ativa, crítica e reflexiva. Conforme Luckesi (2011), é necessário que todos os segmentos escolares aprendam a viver a experiência da gestão democrática para que possam de fato viver a democracia. Acrescenta ainda que "a própria sala de aula é um lugar de gestão e, principalmente, de aprendizagem da gestão democrática, não só da escola, mas da vida” (LUCKESI, 2011, p. 226). Dessa forma, implementar estratégias de avaliação que fugiam as tradicionais provas é um exercício para aprender e vivenciar a 
democracia e também para desenvolver a cultura da participação.

O compartilhamento de responsabilidades durante o processo avaliativo contribui para que todos sintam-se partícipes do sucesso ou dos desafios da sala de aula. Ao assumir-se com protagonistas no processo avaliativo, o aluno poderá vivenciar uma situação de gestão da aprendizagem e, dessa forma, com o coletivo poderá fazer proposições, que poderão ser aceitas por mais integrantes do grupo ou ser rejeitada. Dessa forma, vivencia-se o processo democrático, o respeito pela opinião alheia, a decisão coletiva entre outros. Ou seja, a sala de aula é um local especial para formar sujeitos participativos.

A estratégia 3 foi a mais interessante do ponto de vista do exercício de participação, apesar da resistência inicial. Essa abertura para os alunos analisar e avaliar os diferentes momentos das sequências didáticas permitiu que os mesmos se envolvessem mais, seja nas aulas posteriores ou nas rodas de conversa posteriores. Conforme Luckesi (2011), a avaliação deve ter um caráter participativo, a partir de instrumentos adequados de avaliação, para que professor e turma possam discutir o estado da aprendizagem e a partir desses resultados, elaborar e transformar as situações para que todos alcancem a construção de conhecimentos. Nesse sentido, extrapolar as estratégias de avaliação pode ajudar a superar a apatia que muitas vezes está presente.

Muitas vezes, docentes reclamam que as turmas não participam. No entanto, em geral não se dá muita abertura para que os alunos participem ou que analisem as atividades realizadas. Foi possível verificar que, ao preparar momentos planejados nos quais os alunos teriam um espaço para avaliar a aula e realizar uma autoavaliação, houve uma aproximação entre alunos e a docente. Outro aspecto positivo para a docente foi o fato de reconhecer estratégias que acabavam levando a indisciplina ou mesmo desmotivando para a participação da aula. Por outro lado, planejar momentos de avaliação participativa também permitem ultrapassar o autoritarismo da avaliação, no qual apenas um dos atores normalmente tem voz e vez (LUCKESI, 2011) - o professor.

Tudo que é diferente, que sai da zona de conforto individual gera estranhamento. Não foi diferente com as estratégias avaliativas propostas. No entanto, com a insistência no uso dessas estratégias ao longo do ano letivo, houve a aceitação gradual das mesmas e aos poucos, constituiu-se um ambiente organizado e produtivo acerca das informações obtidas. Um aspecto observado foi o estabelecimento de uma atitude de colaboração nas salas de aula, tornando a prática pedagógica mais agradável para os alunos e também para o professor.

\section{Considerações e perspectivas}

Muitos ainda consideram a prática avaliativa o tendão de Aquiles da atividade educacional. Existe uma cultura da avaliação na qual o processo avaliativo é um "problema", 
tanto para o professor quanto para o aluno. No entanto, a avaliação é uma atividade que pode contribuir para que aluno e professor tenham consciência sobre o que já foi compreendido e o que ainda representa uma dificuldade. Nesse caso, é necessário superar a visão de avaliação classificatória, ou seja, aquela que tem como fim obter uma nota, a partir da qual o aluno é aprovado ou reprovado.

Ao dar início a aplicação das estratégias de avaliação diferenciadas, houve resistência por parte de alguns estudantes. Em parte, isso é normal em função dessas estratégias propor a participação, o que leva a desacomodar o aluno do papel passivo frente ao processo avaliativo. Nesse sentido, vale ressaltar a importância de persistir e insistir na utilização de atividades avaliativas como as propostas nesse relato ou outras que não sejam corriqueiras, a fim de obter resultados.

Inúmeras vezes, educadores e demais setores da sociedade reclamam da apatia ou falta de iniciativa do cidadão. No entanto, temos que refletir e questionar se a escola enquanto um espaço de formação incentiva a participação. Incentivar a participação vai além de ouvir as demandas. Significa incluir os indivíduos no planejamento, na proposição de soluções ou em propostas inovadoras, ter voz e vez durante a tomada de decisão e nos momentos de análise do processo. A implementação da proposta aqui relatada teve como finalidade plantar a semente da participação entre os participantes. Foram observados vários aspectos positivos.

A utilização da estratégia de autoavaliação ao final de cada aula revelou-se uma atividade inicial para exercitar a tomada de consciência dos alunos acerca de atitudes e aprendizagens. A estratégia de atividades de produção no lugar das provas, tinha como objetivo considerar aspectos conceituais e a criatividade, a capacidade de utilizar a informação em contextos diversos bem como eliminar situações de branco e nervosismo, típicos em provas. Por fim, estratégia de roda de conversa, foi uma forma de perceber que a avaliação se dá em vários níveis e momentos. Nesta, foi necessária uma postura de ouvir e falar respeitosamente, participar de discussões e expressar de forma respeitosa a transformação ou alteração de métodos por parte da docente e de atitudes, por partes dos estudantes.

Por ser um trabalho com objetivo exploratório em relação ao tema avaliação, as observações permitem afirmar que vale a pena adentrar em estratégias avaliativas diferenciadas, apesar da resistência inicial de alguns estudantes. Além disso, é possível apontar perspectivas de pesquisa e estudos a partir do panorama descrito. Dentre estas, citamos a necessidade de realizar estudos de caso, a fim de analisar como ocorrem os processos de autoavaliação, a fim de aprender sobre maneiras mais eficientes na utilização dessa estratégia junto aos alunos.

Aponta-se como necessidade realizar estudos comparativos acerca de resultados em avaliações no estilo prova e no estilo de elaboração/produção de materiais, bem como a 
adequação desse formato avaliativo no caso de preparação para avaliações realizadas a nível nacional, como a Prova Brasil. Por fim, seria de extrema valia um estudo longitudinal em relação a estratégia de rodas de conversa (estratégia 3) a fim de acompanhar a longo prazo como essa técnica conduz à melhoria da cultura da participação e a seus possíveis efeitos sobre a comunidade/sociedade.

A gestão escolar democrática foi uma conquista e ainda vive sua juventude. No entanto, é importante valorizar estudos e práticas que conduzam a sua maturação, a fim de que se perceba seus efeitos na vida em sociedade. Repensar o modo como a escola conduz o processo avaliativo, utilizando seu potencial no desenvolvimento de uma cultura da participação pode ser um caminho para consolidar um modelo de sociedade centrado no respeito, valorização das diferenças, responsabilidade compartilhada e desenvolvimento humano.

\section{Referências}

ANDRADE, M. M. Introdução a metodologia do trabalho científico: elaboração de trabalhos na graduação. 9. ed. São Paulo: Atlas, 2009.

DEMO, Pedro. Avaliação qualitativa. $8^{\mathrm{a}}$ ed. São Paulo: Editores Associados, 2005.

DELIZOICOV, D.; ANGOTTI, J.; PERNAMBUCO, M. Ensino de ciências: fundamentos e métodos. $4^{\mathrm{a}}$ ed. São Paulo: Cortez, 2011.

FLICK, U. Introdução à Metodologia de Pesquisa. Porto Alegre: Penso, 2013.

FREIRE, Paulo. Pedagogia da autonomia: saberes necessários à prática educativa. São Paulo: Paz e Terra, 1996.

GATTI, Bernardete. O professor e a avaliação em sala de aula. Estudos em Avaliação Educacional, n. 27, p. 97- 114, 2003.

GIL, Carlos. Métodos e Técnicas de Pesquisa Social. $6^{\mathrm{a}}$ ed. São Paulo: Atlas, 2008.

LIBÂNEO, José Carlos. Didática. $2^{a}$ ed. São Paulo: Cortez, 2013.

LUCKESI, Cipriano Carlos. Avaliação da aprendizagem escolar. $22^{a}$ ed. São Paulo: Cortez, 2011.

MENEGHEL, Sílvia Maria; KREISCH, Cristiane. Concepções de avaliação e práticas avaliativas na escola: entre possibilidades e dificuldades. EDUCERE, n. 9, p.98199831, 2009.

PERRENOUD, Phillipe. Avaliação: da excelência à regulação das aprendizagens - entre duas lógicas. Porto Alegre: ArtMed, 1999.

POLTRONIERI, Helena; CALDERÓN, Antonio. I. Avaliação na educação básica: a revista estudos em avaliação educacional. Estudos em Avaliação Educacional, v. 23, n. 53, p. 82-103, 2012. 
SAUL, Ana Maria. Referenciais freireanos para a prática da avaliação. Revista de Educação PUC Campinas, n. 25, p. 17-24, 2008.

THIOLENT, Michel. Metodologia da pesquisa-ação. 16 ed. São Paulo: Cortez, 2008.

\section{Biografia Resumida}

Raquel Ruppenthal: Licenciada em Ciências Biológicas (UFSM). Mestre e Doutora em Educação em Ciências: Química da Vida e Saúde (UFSM). Professora Adjunta Universidade Federal do Pampa - Campus Uruguaiana (UNIPAMPA, Uruguaiana-RS). Integrante do Grupo de Estudos e Pesquisa em Estágio e Formação de Professores (GEPEF - UNIPAMPA).

Contato: raquelruppenthal@unipampa.edu.br

$\mathrm{ou}$ rkruppenthal@gmail.com.

Link do lattes: http://lattes.cnpq.br/6918823752779978

Cadidja Coutinho: Licenciada em Ciências Biológicas (UFSM). Mestre e Doutora em Educação em Ciências: Química da Vida e Saúde (UFSM). Professora Adjunta Universidade Federal do Pampa - Campus Dom Pedrito (UNIPAMPA, Dom Pedrito-RS). Integrante do Grupo de Pesquisa em Práticas de Ensino em Ciências (GPPEC - UNIPAMPA).

Contato: cadidjacoutinho@unipampa.edu.br ou cadidjabio@gmail.com .

Link do lattes:http://lattes.cnpq.br/9429704945665907

Mara Regina Bonini Marzari: Licenciada em Química (UFSM). Mestre em Química e Doutora em Ciências com ênfase em Química Orgânica (UFSM). Professora Adjunta Universidade Federal do Pampa - Campus Uruguaiana (UNIPAMPA, Uruguaiana-RS). Integrante do Grupo de Estudos e Pesquisa em Estágio e Formação de Professores (GEPEF - UNIPAMPA).

Contato: maramarzari@unipampa.edu.br ou marabmarzari@gmail.com

Link do lattes: http://lattes.cnpq.br/2047536712039793 